\title{
Methodology for IT Governance Assessment and Design
}

Sérgio Clementi, Tereza Cristina M. B. Carvalho

\author{
Fundação Santo André \\ sergio,clementi@fsa.br \\ Laboratory of Computer Architecture and Networks - Escola Politécnica \\ University of São Paulo \\ carvalho@larc.usp.br
}

\begin{abstract}
IT Governance has become an increasingly important process in delivering business value from IT. A number of IT governance frameworks have been proposed as the MIT - CISR framework and COBIT. However, there is no proposal of a systematic methodology for IT Governance assessment and design, considering the possibility of joint usage of multiple frameworks. This paper presents a systematic methodology for IT governance assessment and design, specified through different phases, their activities and outcomes. This methodology is applied in a real case showing the practical benefit from its usage.
\end{abstract}

\section{Introduction}

IT Governance has become an increasingly important topic for most of the enterprises. In North America and Western Europe the increasing investments in IT (around $4.2 \%$ of the annual revenues) have focused attention on ensuring that IT delivers value [2]. Similar trends have been observed in Brazil, where, according to FGV-EAESP [10], the average investments in IT have also increased: in 1988, it was $1.3 \%$ of the net revenue, while in 2003 it went up to $4.9 \%$ of the net revenue.

Nowadays, IT is completely embedded in the enterprises and it is expected that new IT technologies would bring new business opportunities to the enterprises. According to [2], firms with focused strategies and good IT governance have more than $\mathbf{2 0 \%}$ higher profits than other firms following the same strategies. 
In this sense, IT governance is an important process in delivering business value from IT and mitigating IT risks. This paper presents a systematic methodology for IT governance assessment and design, specified through different phases, their activities and outcomes. Applying this methodology, the business objectives are mapped onto IT business role; and the decisions to be taken, the archetypes for making IT decisions, and the mechanisms for implementing and assessing IT Governance are defined. So, the main research contribution of this paper is the theoretical and practical sides of a methodology for IT governance assessment and design.

This paper has 6 sections in addition to this introductory one. The second section discusses some basic concepts about which is considered IT Governance. The third section presents an overview of the MIT-CISR IT Governance framework that is taken as basis for the development of the methodology proposed in this paper. The fourth section describes the proposed methodology for IT Governance design and assessment composed of different phases, detailing, for each phase, their activities and the expected outcomes. In the fifth section, it is discussed the validation of this methodology considering some scientific checking criteria and its practical application. In the last section, some conclusions and final discussions are presented.

\section{IT Governance Concept}

But what is IT Governance? For Peterson [4], IT Governance is the system by which an organization's IT portfolio is directed and controlled. IT Governance describes: the distribution of IT decision-making rights and responsibilities among different stakeholders in the organization; and the rules and procedures for making and monitoring decisions on IT strategy.

Weill and Ross [2] state "Governance is about systematically determining who makes each type of decision (a decision right), who has input to a decision (an input right) and how these people (or groups) are held accountable for their role". In this case, IT Governance is responsible for specifying the decision rights and accountability framework to encourage desirable behavior in the use of IT.

COBIT considers IT Governance as being a structure of relationships and processes to direct and control the enterprise, achieving the enterprise's goals by adding value while balancing risk versus return over IT and its processes [1][5].

From these definitions, it can be said that IT Governance is focused on [3][8]:

- Creation of business value (strategic alignment).

- Preservation of business value (risk management).

\section{Overview of the MIT-CISR Framework}

The MIT-CISR framework is built up over six components (see in Figure 1)[2]:

- Enterprise strategy and organization: provide the direction for IT structure and desirable behaviors motivating governance. 
- IT governance arrangements: assign decision rights to different IT archetypes for key decisions aiming to achieve business performance goals.

- Business performance goals.

- IT organization and desirable behaviors are aligned and harmonized with the enterprise strategy and organization.

- IT metrics and accountabilities define how IT will contribute to the enterprise performance goals and provide means for assessing the IT effectiveness.

- IT governance mechanisms: provide tools for implementing and supporting the IT governance decisions. They cover decision-making organizational structures; alignment processes (e.g., SLA) and communication approaches.

\begin{tabular}{|c|c|c|}
\hline 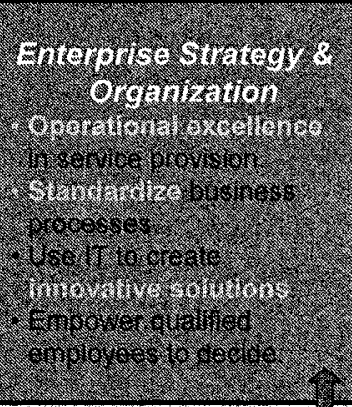 & 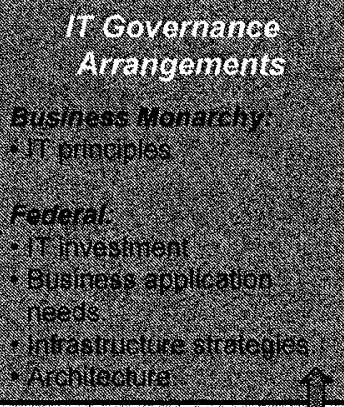 & 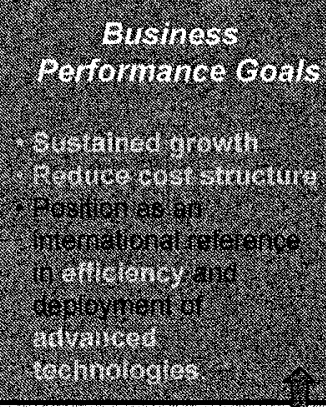 \\
\hline $\begin{array}{l}\text { IT Organization \& } \\
\text { Desirable Behavior } \\
\text { - Develop project process } \\
\text { and technical } \\
\text { competence within IT. } \\
\text { Optimize and standardize } \\
\text { process, project } \\
\text { procedures and } \\
\text { technology platforms. } \\
\text { Multiple support levels. }\end{array}$ & $\begin{array}{l}\text { IT Governance } \\
\text { Mechanisms } \\
\text { IT Governance } \\
\text { committee } \\
\text { Project steering board } \\
\text { lead key IT } \\
\text { Implementation. } \\
\text { ITIL tools for problem } 8 \\
\text { lncident management. } \\
\text { System \& net mgmt. } \\
\text { - SLA . Intranet for communication }\end{array}$ & $\begin{array}{l}\text { IT Metrics } \\
\text { \& Accountabilities } \\
\text { - KPI (Key Performance } \\
\text { Indicators) on service } \\
\text { quality. } \\
\text { - Standards adoption } \\
\text { Responsiveness to } \\
\text { customer needs and } \\
\text { claims. }\end{array}$ \\
\hline
\end{tabular}

Fig. 1. Example of the Governance Design Framework

In addition, this framework defines IT decision types and IT archetypes. The defined IT decision types are: IT principles (IT business role); IT architecture; IT infrastructure; business application and IT investment. The IT archetypes specify who is responsible for IT decisions and include: business monarchy (top managers); IT monarchy (IT specialists); Feudal (BU - Business Units); Federal (corporate members, BUs and, optionally, IT people); IT duopoly (IT group and another group) and Anarchy (not well defined) [2]. The IT archetypes and decisions are used to develop the Governance Arrangements Matrix (Figure 2 shows a Governance Matrix 
example). In this matrix, it is presented which archetypes contribute (input) to the decision-making processes and which ones (decision) really take the decisions.

\section{IT Governance Methodology}

The proposed methodology presents a systematic way to design the IT Govemance for an enterprise:

- It is described in terms of different phases and their relationship.

- It specifies the inputs, the procedures and the expected results for each phase.

It takes as basis the Governance Arrangements Matrix and the Governance Design Framework proposed by Weil and Ross in [2], described in Section 3.

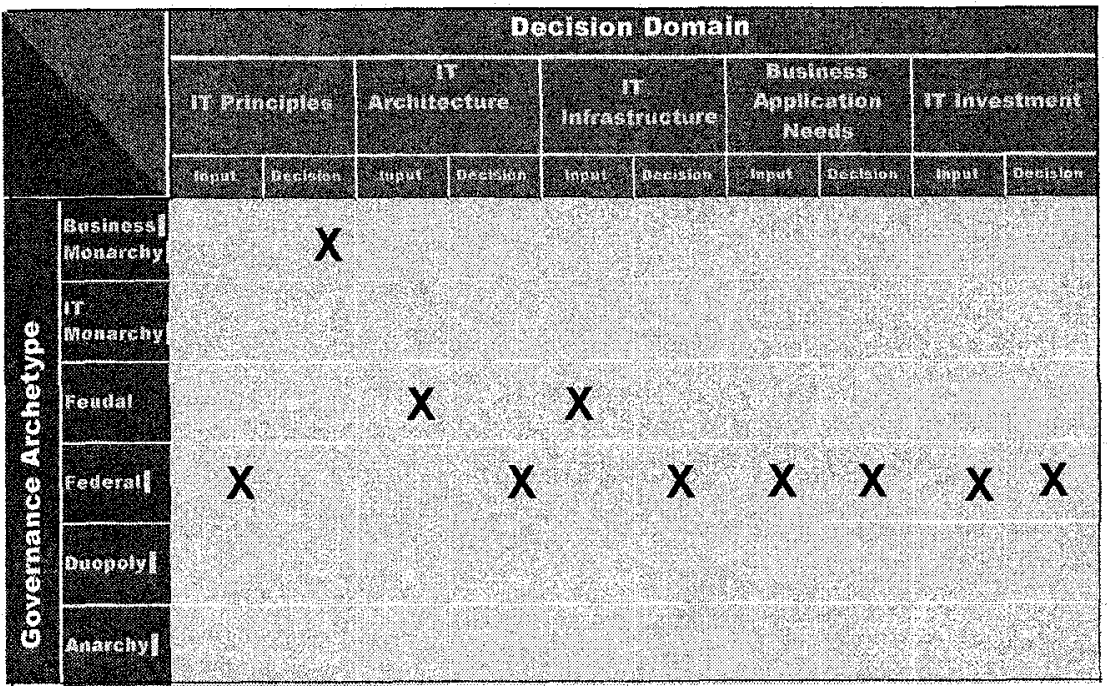

Fig.2. Example - IT Computer Center Governance Arrangements Matrix

The phases of this methodology are (Figure 3):

- Phase 1 - Enterprise Setting Information: its purpose is to acquire basic knowledge about the company and the IT Governance status.

- Phase 2 - Assessment of IT Governance Performance: in this phase, it is identified the IT decision makers and contributors, the adopted IT Governance mechanisms and how the IT Governance results are evaluated in terms of financial metrics and effective use of the IT resources.

- Phase 3 - Redesign of IT Governance. Based on the analysis of the previous phases, the IT governance is reviewed taking into account the decision makers, the effectiveness of the IT governance mechanisms and the business performance goals versus IT Governance metrics and accountabilities.

- Phase 4 - Implementation of the New IT Governance. In this phase, it is planned how a New IT Governance will be implemented considering the activities 
to be developed, the necessary human resources and the time for their execution. The IT Governance implementation plan is executed and continuously evaluated.

- Phase 5 - Assessment and Management of IT Governance. Based on the metrics and accountability indicators previously specified, the IT governance effectiveness is evaluated. If some problems are detected, the IT mechanisms and behaviors are analyzed and reviewed.

\subsection{Phase 1 - IT Governance Settings}

Before deciding for one IT Governance Framework or another, it is important to assess the enterprise settings. The enterprise settings capture the industry, the basic strategy, the size, the number of Business Units and the relationship among them.

First of all, it should be understood which basic strategy guides the enterprise. As basis, the following three value disciplines can be considered [9]:

- Operational Excellence: emphasizes efficiency and reliability, leads the industry in price and convenience, minimizes overhead costs and streamlines supply chain.

- Customer Intimacy: focuses on customer relationships, lifetime, service, responsiveness and customization based on its deep knowledge.

- Product (Service) Leadership: prioritizes continuous product innovation, embracing new ideas and solutions with rapid commercialization.

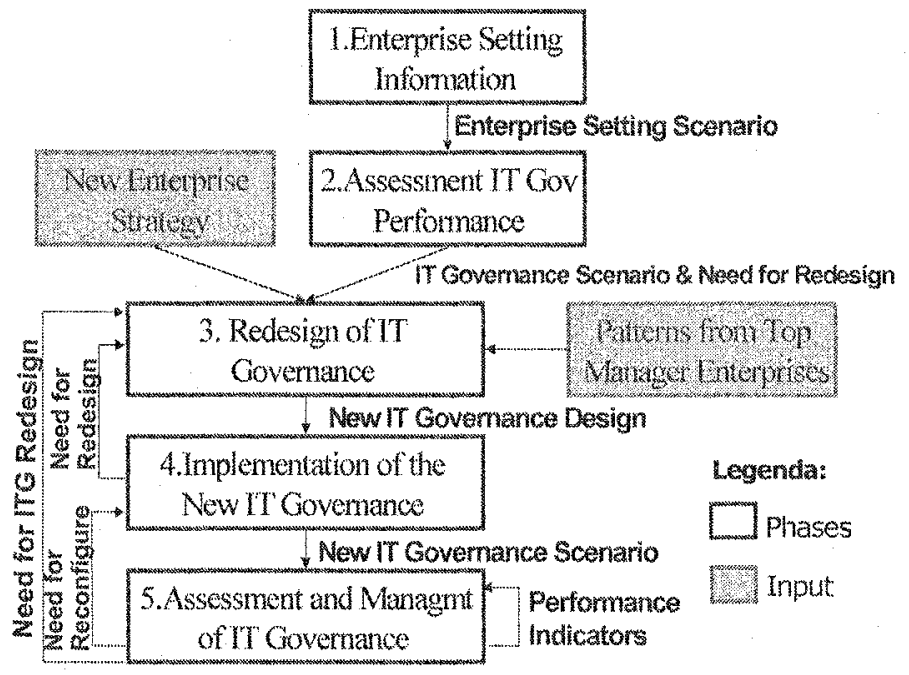

Fig. 3. General Overview of the Methodology

In addition, it is considered the organizational design that reflects the firm size (number of BUs) and the synergy level between these BUs - centralized management (high BU synergy) or distributed management (BU autonomy) structures. Other 
important aspects include the environment stability and the performance goals, as: profit (ROI or ROE); asset utilization (ROA); and revenue growth.

This phase will result in the description of the Enterprise Setting Scenario.

\subsection{Phase 2 - Assessment of IT Governance}

In this phase, the IT decision makers and contributors, the adopted IT Governance mechanisms and how the IT Governance results are evaluated in terms of financial metrics and effective use of the IT resources are identified. For this purpose, the following activities are performed (Figure 4):

- Map the enterprise's current governance onto the Governance Arrangements Matrix and the Governance Design Framework.

- Audit the current IT Governance mechanisms.

- Identify the types of IT Governance mechanisms (decision-making, alignment and communication mechanisms), how they are defined, how they are applied, their objectives, their expected desirable behaviors, their effectiveness and how this effectiveness is evaluated.

- Evaluate the IT Governance awareness and engagement.

- Audit IT Governance Metrics and Accountabilities.

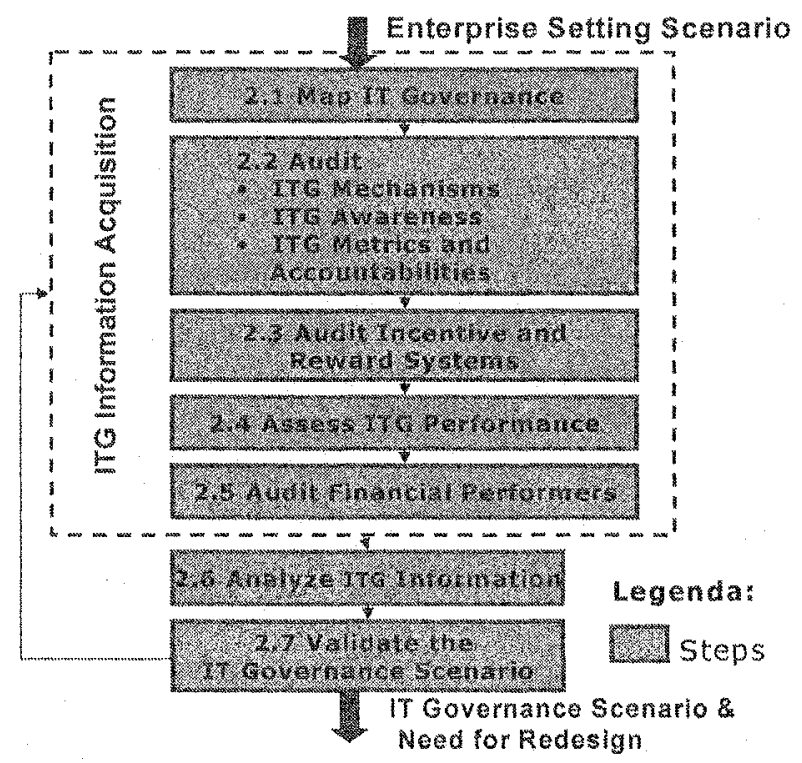

Fig, 4. Phase 2 - Assessment of IT Governance

- Audit incentive and reward systems, verifying if they are aligned with the organizational goals.

- Assess the IT Governance performance in terms of the importance of its outcomes, the impact on the business and in which enterprise areas it works best 
and worst. The effective use of IT for cost control, growth, asset utilization and business flexibility is evaluated.

- Audit Financial Performance considering the business goals (e.g., profit - ROE, ROI, percent margin, asset utilization, growth - percentage change in revenue).

The acquired data is analyzed identifying the enterprise's strategy, which kind of IT decisions has been taken under IT Governance, who are the decision makers, how the decisions are made and monitored, how the performance goals have been achieved. As result, it is obtained the current IT Governance scenario. The current IT Governance scenario is presented to the enterprise's board for validation. It should foster discussions about the IT Governance status related to current positive outcomes, inefficiencies and improvement goals, defining which key performance indicators should be prioritized. As result of this phase, the IT Governance scenario is described and some specific needs for redesign are identified.

\subsection{Phase 3 - Redesign of IT Governance}

Based on the analysis of the previous phases, the IT governance is reviewed considering the decision makers, the IT governance mechanisms effectiveness and the business performance goals versus IT Governance metrics and accountabilities (Figure 5). Thus, the Governance Design Framework is reviewed through:

- Redefinition of the strategy mission, making clear the strategy intent through a clear, concise statement;

- Identification of new desirable behaviors in harmony with the strategic direction (e.g., process optimization in harmony with the operational excellence strategy).

- Review of the IT Governance arrangements (decision makers and contributors versus types of decisions to be taken (Section 3) and identification of the actions to be taken to improve its harmonization with enterprise strategy and organization.

- Review of the business performance goals (e.g., ROI or profits), stating clearer business objectives (e.g., cost reduction, the customer retention improvement) for IT Governance and a benchmark for assessing the success of governance efforts.

- Identification of the need for new IT Governance mechanisms or the reduction of their number (well-designed mechanisms reinforce and encourage desirable behaviors and lead to outcomes specified in the IT metrics and accountabilities).

- Review of the IT Governance Metrics and Accountabilities, verifying if they are harmonized with the business performance goals.

- Review of the IT Governance communication approaches. 


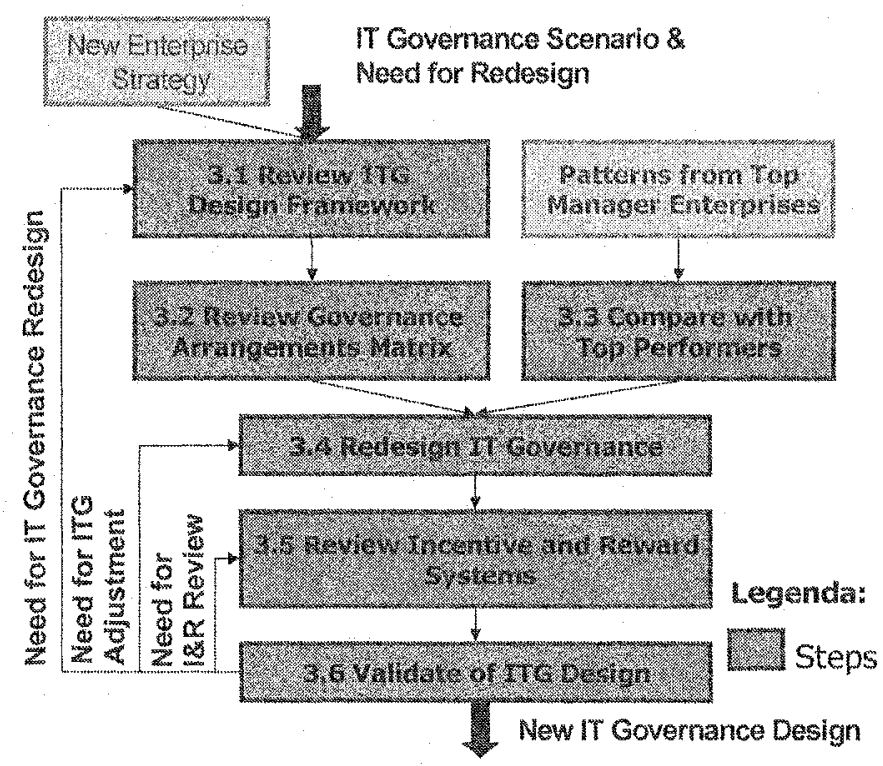

Fig. 5. Phase 3 - Redesign of IT Governance

Based on the new resulting Governance Design Framework, the Governance Arrangements Matrix is also reviewed. Then, the Governance Design Framework and the Governance Arrangements Matrix are compared with those ones of similar top performer enterprises in terms of culture, structure, strategy and business goals. It can be taken as reference the research results published in [12]. The differences are identified and evaluated, verifying the need for IT Governance redefinition.

The redesign of the IT Governance is completed, identifying the changes to be made in the Governance Design Framework, the Governance Matrix Arrangements, the IT Governance mechanisms, the IT Governance metrics and accountabilities. In addition, the Incentive and Reward Systems is reviewed to assure that they are aligned with the organizational goals.

The new IT Governance design is presented and discussed with the enterprise's leaders (e.g., senior managers) and/or with the person or group of people responsible for the IT Governance implementation. As result, it can be necessary to do some adjustments and reviews in the IT Governance design or even redesign it.

The main outcome of this phase is the New Design of the IT Governance.

\subsection{Phase 4 - Implementation of The New IT Governance}

In this phase, the IT Governance implementation plan is detailed, executed and continuously evaluated (see Figure 6). The plan for the implementation of the new IT Governance is detailed, describing the activities of each phase of implementation, the necessary resources and time for its execution besides its expected outcomes. This IT 
Governance implementation plan is presented and discussed with the IT and/or BU's leaders. Once the plan has been approved, its execution can start.

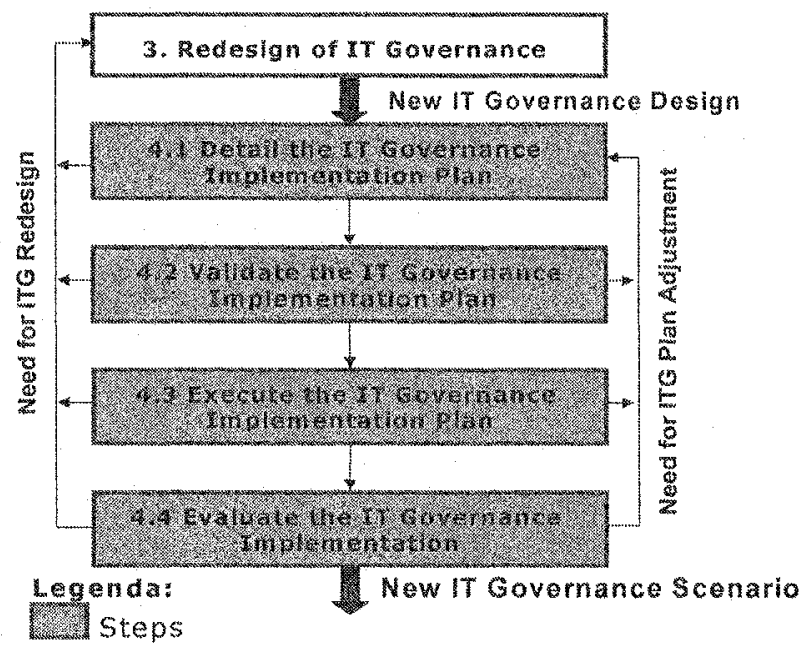

Fig. 6. Phase 4 - Implementation of The New IT Governance

At this point, the enterprise can decide for its implementation internally or by a third party company. In the first case, it should proceed allocating the necessary resources and the team responsible for different IT Governance activities and, programming the necessary training and launching its start. The execution of the IT Governance implementation and its milestones should be constantly evaluated as well the employees reaction to the undergoing changes. However, if the enterprise has decided for outsourcing the IT Governance implementation, at first it has to define how the outsourced company will be selected considering previous experience, team qualification, cost and time to deliver the IT Governance implementation, among other relevant features for the enterprise. Once the outsourced company has been selected, the other activities to be performed are basically the same as in the case of internal implementation. The firm's employees will be involved in a lower degree but they will have to work together with the outsourced company's team to guarantee the IT Governance implementation success.

At this phase end, a new IT Governance scenario will have been implemented.

\subsection{Phase 5 - Assessment and Management of IT Governance}

Based on the metrics and accountability indicators specified previously, the IT Governance effectiveness is evaluated. If some problems are detected, the IT mechanisms and behaviors are analyzed and reviewed (see Figure 7). 


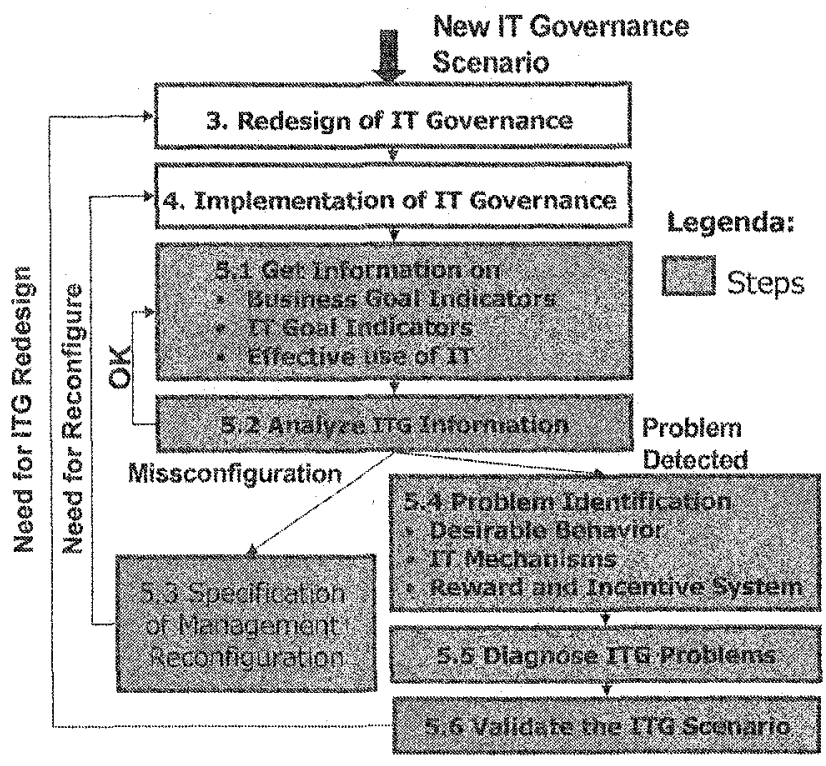

Fig. 7. Assessment and Management of IT Governance

In this phase, at first it is collected information about the financial performers, the customer perspective in relation to the enterprise, the employee performance, product and service innovation capability, need for new business indicators, the evaluation of the IT efficiency and reliability taking as reference the predefined IT metrics, the need for IT metrics, the evaluation of the effective use of IT related to cost control, asset utilization and business alignment, among other specific issues important for each business.

As result of this information analysis, it can be decided for the system management reconfiguration, introducing new IT metrics and/or business indicators or even modifying the target values for such metrics and indicators. This analysis allows identifying problems with the IT desirable behaviors, the IT mechanisms efficiency, and the Incentive and Reward Systems impact on the IT governance goals.

This analysis serves as basis for the IT Governance diagnose to be discussed with the IT and business leaders. As consequence, it can be decided for IT Governance adjustment or redesign.

In Figure 3, it can be verified that these phases are not necessarily executed in sequence. The transition from the current phase to any other will depend on the outcomes got from the current phase. For instance, the assessment of IT Governance in Phase 5 can result in its redesign (Phase 3) or reconfiguration (Phase 4). 


\section{Methodology Validation}

As it was already mentioned the proposed methodology took as basis the MIT-CISR framework for IT Governance design and assessment and its IT Governance research carried out in around 250 enterprises. The basis of this research allows us to assure the practical benefit from the application of the proposed methodology in the IT Governance design and assessment of the nowadays enterprise.

\section{Methodology Effectiveness}

According to [11], an effective methodology must fulfill the following requirements:

- Formal description - A methodology must consist of a set of operations or activities specified in a written, graphical or algorithm forms or any combination of these forms as long as it meets the need for no ambiguity.

- Definable activities - The activities must be capable of definition.

- Complete transformation - The transformation must be essentially complete, i.é, no additional activity must be necessary in order to produce a usable result.

- Implementable actions - all activities must be capable of implementation.

The proposed methodology for IT Governance design and assessment satisfies the criteria defined in [11]. The methodology is described in a systematic manner, detailing its phases and the activities of each phase. These activities are defined allowing the use of the proposed methodology by any enterprise that wants to design or assess its IT Governance. The complete transformation is achieved; being described the input and the outcomes of each phase. All the specified activities are capable of implementation as it is shown in the case study described in the next item.

Additionally, the proposed methodology supports the fulfillment of the critical success factors of the IT Governance, identified as [2]:

- Transparency: More transparency in the process of IT Governance implementation normally results in more confidence from the enterprise employees (e.g., communication approaches as IT Governance mechanism).

- Engagement and education: the managers should be educated and engaged in this process (e.g., usage of communication approaches and different archetypes for different types of decision).

- Ownership: it should be ensured that IT governance is owned and has metrics and incentives (e.g., use of the Governance Arrangements Matrix and IT metrics and accountabilities).

- Alignment between incentives and metrics: Unaligned incentives and metrics governance destroy governance (e.g., requirement of alignment between desirable behavior and enterprise strategy \& organization).

- Governance Design: the IT Governance should be designed at enterprise and BU levels. It should be known when it has to be redesigned (e.g., usage of the Governance Arrangements Matrix and the IT Governance Design Framework for IT Governance assessment and design). 


\section{Case Study}

A case study was developed aiming to validate the proposed methodology. It was considered the IT center of a large public university, whose mission is to provide IT services to the university community such as: networking, data content hosting, IT security and management, equipment maintenance and IT usage support. Nowadays, this community is composed of 60,000 students (undergraduate and graduate), 5,000 faculty members and 15,000 staff people. This IT center is organized in 5 divisions (networking, datacenter, multimedia services, maintenance and HR).

Following the proposed methodology, initially it was got information about the organization setting. The main goal of this IT center is to have operational excellence in service provision in terms of efficiency and reliability, reducing at same time costs. Its five divisions present high synergy and they are aligned with the IT center core to maximize the ROA, increasing the resources reusability as much as possible.

In the second phase, the IT governance was mapped and we got the Governance Arrangements Matrix and the IT Governance Design Framework (Figures 2 and 1). As it can be seen in the ITG framework, to achieve the proposed goal, it is necessary to optimize and standardize the processes and project procedures and count on employees with very good technical background and highly committed with the organization goals. The evaluation of IT service quality is performed through the measurement of KPIs (Key Performance Indicators) related to service quality and responsiveness to customer needs and claims through proactive problem detection and correction, short time to problem solving, fault recovery and equipment maintenance. In this case, the IT Governance is enforced by several mechanisms such as committees, system and network management and intranet communication.

In the third phase, it was identified as priority to improve the mechanisms and promote a better integration between the organization divisions. In the case of mechanisms, it was decided to follow the ITIL [13](Information Technology Infrastructure Library) approach and focus on the problem and incident management disciplines, considered the most critical ones. It implied the integration of service desk, data center, networking and maintenance divisions in order to guarantee shorter time to problem solving, fault recovery and equipment maintenance.

In the fourth phase, the ITIL problem and incident management disciplines implementation was planned and executed. It was performed with the consultancy of an external company, which provided also the ITIL software system and tools.

Nowadays, in the last phase, we are collecting information about the outcomes got from the implemented IT Governance system and refining some processes. As soon as these tasks are completed, we intend to incorporate new ITIL disciplines in our ITG systems. As first results, we have verified that the time to solve problems and perform equipment maintenance has reduced and when it is not the case, we are able to give a better feedback to our customer.

\section{Final Considerations}

A number of IT governance frameworks at different levels of analysis have been proposed as the MIT - CISR framework and COBIT [1]. However, it has not been 
developed yet a methodology that allows the implementation of IT Governance in a systematically and gradually way.

This paper proposes a methodology for IT Governance design and assessment detailed in a systematic way through the description of its phases, the corresponding activities and outcomes of each phase. It took as basis the MIT-CISR framework that is very simple and practical once it is based on field research in enterprises of different sizes, strategies and industry branches.

The proposed methodology supports the usage of different frameworks simultaneously [12]. In the presented case study, it was adopted the ITIL. The selection of the proper IT Governance mechanisms depends mainly on the enterprise strategy and performance goals as it discussed in Section 4.

Finally, it should be emphasized that the proposed methodology can be adopted by enterprises, which want to implement the IT governance from scratch or need to redesign already existing IT governance. In both cases, the process of IT Governance implementation can be performed gradually.

\section{Acknowledgment}

The authors thank Peter Weill from the MIT-CISR for all the support given to the development of the methodology proposed in this paper.

\section{References}

1. IT Governance Institute. COBIT $-4^{\text {rd }}$ edition, (IT Governance Institute, Rolling Meadows, IL, 2005), http://www.itgi.org/

2. P. Weill and J. R. Ross, IT Governance: How Top Performers Manage IT Decision Rights for Superior Results, (Harvard Business School Press, Harvard, 2004).

3. W. V. Grembergen, S de Haes and E. Guldentops, Structures, Processes and Relational Mechanisms for ITGovernance, in: Strategies for IT Governance edited by W. V. Grembergen (IDEA Group Publishing, Hershey, PA, 2004), pp. 1-36.

4. R, R. Peterson, Integration Strategies and Tactics for Information Technology Governance, in: Strategies for IT Governance edited by W. V. Grembergen (IDEA Group Publishing, Hershey, PA, 2004), pp. 37-80.

5. E. Guldentops, Governing Information Technology through COBIT, in: Strategies for IT Governance edited by W. V. Grembergen (IDEA Group Publishing, Hershey, PA, 2004), pp. 269-310.

6. T. C. M. B. Carvalho, P. Weill and S. Clementi, IT Governance Frameworks, in: International Congress Business Intuition, 2004, Riga. (FOIL, Riga, 2004). 
7. S. Clementi, E. A. Sortica and T. C. M. B. Carvalho, IT Governance: A Virtual Enterprise under COBIT and ITIL assessment, in: SLADE 2004 - XVII Congresso latino Americano de Estratégias. Camboriú - SC, April 2004 (SLADE, Camburiu, Brazil, 2004).

8. S. D. Haes and W. V. Grembergem, IT Governance Structures, Processes and Relational Mechanisms: Achieving IT/Business Alignment in a Major Belgian Financial Group, in: 38th Hawaii International Conference on System Sciences (HICSS-38 2005) / Abstracts Proceedings, 3-6 January 2005, Big Island, HI, USA. (IEEE, Piscataway, NJ 2005), CD-ROM, 10 pp.

9. M. Treacy and F. Wiersema, The Discipline of Market Leaders (Addison Wesley, Reading, MA, 1995).

10. R. Godinho, Chega de tecnologia. Queremos solução. B2B Magazine, Brazil, (Agosto 2004), pp. 28-36.

11. R. B. Walford, Information Networks, A Design and Implementation Methodology (Addison Wesley, Reading, MA, 1990).

12. T. C. M. B. Carvalho, A Comparative Analysis Between MIT-CISR IT Governance Framework and CobiT, in: Congresso Anual de Tecnologia de Informação - CATI 2005, 2005, São Paulo. Congresso Anual de Tecnologia de Informação - CATI 2005. (FGV-EAESP, São Paulo, 2005), p. 49.

13. Great Britain CCTA - Central Computer and Telecommunications Agency, ITIL (Information Technology Infrastructure Library) - The key to managing IT services (TSO, London, March 2000). 